\title{
THE EFFECTS OF HOLOCENE PODZOLISATION ON RADIONUCLIDE DISTRIBUTIONS AND DOSE RATES IN SANDY COASTAL SEDIMENTS
}

\author{
ASGER H. NIELSEN ${ }^{1}$ and ANDREW S. MURRAY ${ }^{2}$ \\ ${ }^{I}$ Department of Geography \& Geology, University of Copenhagen, \\ Øster Voldgade 10,DK-1350 Copenhagen K, Denmark (e-mail:asn@geogr.ku.dk) \\ ${ }^{2}$ Nordic Laboratory for Luminescence Dating, Department of Earth Sciences, Aarhus University, Risø National Laboratory, \\ Frederiksborgvej 399, DK-4000 Roskilde, Denmark
}

\begin{abstract}
This study analyses the effect of a specific kind of soil development, podzolisation, on selected radionuclide concentrations and the derived dose rates. 100 samples from four sandy, podzolised regions in Jutland, Denmark, were dated by luminescence dating. Dose rates were determined by gamma spectrometry. Of the 100 samples, 31 were retrieved from three profiles intersecting soil horizons affected by podzolisation. At 35 locations, additional material was collected for supplementary geochemical analyses (soil $\mathrm{pH}$, organic carbon content and extractable iron and aluminium). The geochemical data and grain size data were correlated with radionuclide activity concentrations. These correlations do not indicate any significant relationship between organic carbon or extractable iron/aluminium and radionuclide concentrations; this suggests that the radionuclides are mainly internally bound in primary minerals, unlike the extractable iron, which is generally associated with surface coatings. We conclude that the radionuclide distribution in these young sandy soils has been relatively unaffected by the podzolisation process. Thus it appears that the dose rate at these sites is unlikely to have changed significantly with time as a result of podzolisation, because the parent material is relatively unweathered and the activity is dominated by internally bound radionuclides.
\end{abstract}

Keywords: luminescence dating, dose rate, radionuclide activity concentration, gamma spectrometry, podzolisation.

\section{INTRODUCTION}

In luminescence dating it is often assumed that the dose rate has remained constant since the last zeroing of the luminescence signal within the sample (Aitken, 1985). However, radioactive disequilibria, where the activity concentration of a radioactive decay series member is not in secular equilibrium with some or all of the other members of the series, may mean that the radioactivity level measured today is not representative of the levels present, on average, during the burial period of a sediment sample (Vandenberghe, 2004). Such radioactive disequilibrium may disappear over time, if it is not maintained by import and deposition (i.e. open system behaviour) as parent decays replace the missing isotopes. Although minor disequilibria do not usually affect the dose

Corresponding author: A. H. Nielsen

e-mail: asn@geogr.ku.dk

ISSN 1897-1695 (online), 1733-8387 (print) (C) 2008 GADAM Centre, Institute of Physics, Silesian University of Technology.

All rights reserved. rate significantly (Prescott and Hutton, 1995), radioactive disequilibria are widespread in sediments, and some can be severe enough to be of concern (Olley et al., 1996).

The most common disequilibria in sandy sediments, such as those in this study, concern the ${ }^{238} \mathrm{U}$ decay series; the relatively long half-lives of ${ }^{238} \mathrm{U}$ daughters allow the possibility of post-depositional redistribution (Vandenberghe, 2004). Two common examples are ${ }^{222} \mathrm{Rn}$ escape through the porous sediment and ${ }^{210} \mathrm{~Pb}$ deposition on surfaces (Krbetschek et al., 1994), including young, buried surfaces in aeolian sediments. The short half-life of ${ }^{210} \mathrm{~Pb}$ removes any evidence of ${ }^{210} \mathrm{~Pb}$ excess within $\sim 100$ years after burial (Olley et al., 1996). Post-depositional redistribution of uranium and thorium isotopes can also affect the dose rate of sandy sediments. While uranium is especially affiliated with organic matter (Olley, 1994), other colloids with high surface areas are able to trap uranium, thorium and other radionuclides (Talibudeen, 1964) and redistribute them in the soil profile as the colloids are transported through the profile. These colloids 
can be both organic (e.g. humic acids) and inorganic (such as secondary iron and manganese compounds). Organic complexing acids can dissolve uranium and thorium-bearing minerals and keep both elements in the soil solution as complexes, again increasing the mobility of both elements (Harmsen and de Haan, 1980). Radium tends to remain in solution in salty groundwater, giving rise to the potential for deposition of radium at the groundwater surface (Olley, 1994) and thus the establishment of disequilibrium. Although ${ }^{40} \mathrm{~K}$ is the parent of a stable daughter nuclide, the activity can change with time, if ${ }^{40} \mathrm{~K}$ is redistributed along with other isotopes of potassium. However, potassium bound in mineral forms accounts for most of the $\mathrm{K}$ in soils (e.g. 97-98\% of total $\mathrm{K}$ in Delaware soils; Parker et al., 1989). The K-containing minerals are mainly micas and alkalifeldspars (Sparks, 2000); all primary minerals often found as sand sized grains in soils with sandy texture. These grains are relatively immobile in the soil profile, and will only release $\mathrm{K}$ when the minerals are broken down by weathering. Although potassium is a macronutrient, $\mathrm{K}$ in plant materials only accounts for $0.25-0.5 \%$ o of the total soil $\mathrm{K}$ content (based on average $\mathrm{K}$ concentrations given by Scheffer and Schachtschabel, 2002). Hence, plant uptake of $\mathrm{K}$ is unlikely to affect total ${ }^{40} \mathrm{~K}$ activity concentrations, and almost all ${ }^{40} \mathrm{~K}$ is expected to be bound in immobile mineral forms. Nevertheless, in temperate, acid and sandy soils with low CEC values, any $\mathrm{K}$ in the soil solution is rapidly leached out of the soil profile (Sparks, 2000).

In this study examining sandy parent materials in a cool, humid temperate climatic setting, the main soil forming process is likely to be podzolisation. This soil development type has the potential to contribute to radioactive disequilibria as complexing organic acids move from the eluvial topsoil horizons to the illuvial horizons below. Iron and aluminium compounds move together with organic complexes, forming secondary minerals in the illuvial horizons (Lundström et al., 2000). Here, the iron and aluminium hydroxides will precipitate (along with any radionuclides in the mobile compounds) on larger grains and form surface coatings (Buurman and Jongmans, 2005). Consequently, Vandenbygaart and Protz (1995), Hansen and Huntington (1969) and Hansen and Stout (1968) all found evidence of radionuclide redistribution in podzolised soil profiles.

The common occurrence of podzolisation in sediments to which luminescence methods are applied requires that we investigate whether podzolisation affects the dose rates. Argylian et al. (2005) have recommended that one avoids sampling horizons affected by soil development entirely, but this is not always feasible. In aeolian sediments, where podzolisation is widespread, the unaltered aeolian layers intended for dating may be too thin to avoid soil development altogether, or may display an agedepth trend, resulting in a biased interpretation if podzolised horizons are avoided. The presence of ground water may also limit the ability to avoid podzolisation. For these and other reasons, sediments altered by podzolisation may have to be sampled for OSL dating, and this study aims to investigate the effects of podzolisation on the dose rate and so, in turn, on the apparent luminescence age.

Here we investigate radionuclide activity concentrations and dose rates in relatively uniform sandy materials. The samples originate from four different regions in order to minimise site-specific dose rate patterns. After comparing the average dose rates and grain size distributions at the different sampling sites, the importance of the radionuclide composition is investigated by calculating average contributions to the total dose rate. The effects of soil development are then explored in detail in three soil profiles using statistical correlations of radionuclide concentrations, geochemical data and grain size distributions. Finally conclusions are drawn to the importance of podzolisation to the time dependence of dose rates in luminescence dating.

\section{STUDY SITES AND METHODS}

\section{Parent materials and field methods}

100 OSL samples from four regions in Jutland form the basis of this study (Fig. 1). The parent material at all four sites is well-sorted fine and medium-sized (USDA nomenclature, i.e. $100-500 \mu \mathrm{m})$ aeolian and/or coastal marine sands. Podzolic horizons were encountered at all sampling sites within the four areas, except in very young or wet soils. Twenty nine soil horizons, dated by $35 \mathrm{lu}-$ minescence samples, were also sampled for additional geochemical analyses. The OSL samples were collected

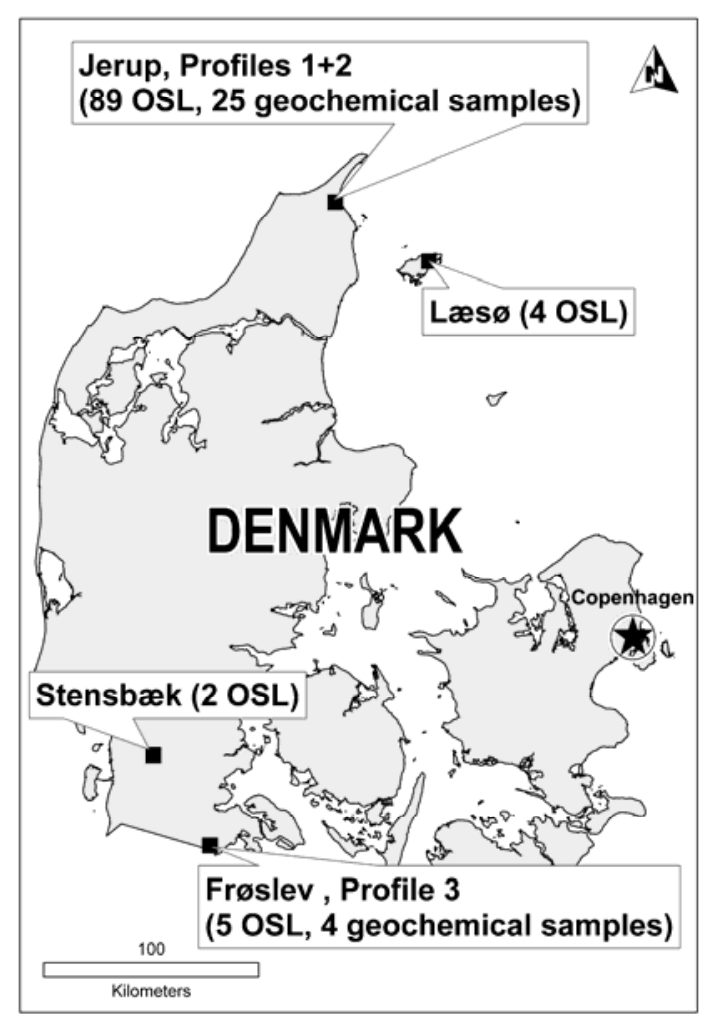

Fig. 1. Map of Denmark showing the distribution of samples and profiles in this study. 
in $25 \mathrm{~cm}$ long PVC tubes $(\varnothing: 4 \mathrm{~cm})$ and sealed immediately after retrieval, while an additional $200 \mathrm{~cm}^{3}$ of sample material for geochemical analyses were collected in zip-lock bags. Three profiles, two in the Jerup area (Northern Jutland) and one in the Frøslev area (Southern Jutland), were also examined in detail. Profile 1 was a seven metre wide and more than two metre deep transect through a beach ridge near Jerup. Here, 16 OSL samples with associated dose rate analyses were collected. The nearby Profile 2 was a standard soil pit, where 10 OSL samples and 5 supplemental samples for geochemical analyses (one sample per soil horizon below the surface organic layer) were retrieved. Profile 3 lies at the edge of a sand pit in Southern Jutland. Five OSL samples and 5 geochemical samples (one of each type per soil horizon) were collected from this profile. The remaining 69 OSL and 20 geochemical samples were collected from horizons without discernible soil development ( $\mathrm{C}$ horizons).

\section{Dose and dose rate determination}

All laboratory processing of luminescence samples was carried out in subdued orange light. The two ends of each sample, potentially exposed to light during sample retrieval, were retained for the non-light sensitive analyses, e.g. assessment of water contents and dose rates. The remaining portion was wet sieved to recover $180-250 \mu \mathrm{m}$ grains. This fraction was etched with $\mathrm{HCl}, \mathrm{H}_{2} \mathrm{O}_{2}, \mathrm{HF}$ and $\mathrm{HCl}$ again to separate a clean quartz separate. OSL measurements were carried out on Risø OSL/TL readers, each equipped with a calibrated ${ }^{90} \mathrm{Sr} /{ }^{90} \mathrm{Y}$ beta radiation source and a blue $(470 \pm 20 \mathrm{~nm})$ light source (Bøtter-Jensen, 1997; Bøtter-Jensen et al., 2000). Prepared quartz grains were attached in a monolayer to a $9.8 \mathrm{~mm}$ diameter stainless steel disc, using silicone oil. A SAR-protocol (Murray and Wintle, 2000 and 2003), with preheat temperatures of $200^{\circ} \mathrm{C}$, cutheat temperatures of $160^{\circ} \mathrm{C}$ and test doses of around $10 \%$ of the estimated natural dose or $0.05 \mathrm{~Gy}$, whichever was larger. The activity concentrations of ${ }^{226} \mathrm{Ra},{ }^{228} \mathrm{Ra},{ }^{228} \mathrm{Th}$ and ${ }^{40} \mathrm{~K}$ were measured by high-resolution gamma spectrometry (Murray et al., 1987); the concentrations of ${ }^{228} \mathrm{Ra}$ and ${ }^{228} \mathrm{Th}$ were indistinguishable, and the weighted average was used to give a ${ }^{232} \mathrm{Th}$ analysis. Dose rates were derived from these radionuclide concentrations, using conversion factors from Olley et al. (1996). The beta attenuation was set to $11 \%$, and alpha radiation contributions were disregarded except for an internal alpha radiation contribution, which was assumed to be $0.06 \pm 0.03 \mathrm{~Gy} / \mathrm{yr}$. A calculated cosmic ray dose rate based on the altitude, latitude and sampling depth (c.f. Prescott and Hutton, 1994) were added to the dose rates. For the purposes of this study, all water attenuation effects were omitted by setting the water content of all samples to $0 \%$ during the dose rate calculations.

\section{Other laboratory analyses}

Soil $\mathrm{pH}$ was measured by a potentiometric method in a 1:2.5 soil and demineralised water solution, using a standard $\mathrm{pH}$ meter with a glass electrode (c.f. Tan, 1996). Organic carbon content was measured on $\mathrm{HCl}$-acidified samples, employing an Eltra CS-500 carbon at $1350^{\circ} \mathrm{C}$
(Eltra, 2002). Extractable iron and aluminium concentrations were obtained by two different complexing agents, sodium citrate-sodium hydrogen bicarbonate-sodium dithionite (CBD) and ammonium oxalate, the latter at pH 3 (c.f. McKeague and Day, 1966). The concentrations of the two elements in either extraction were measured using atomic absorption spectroscopy on two PerkinElmer AAS (2380 and 3110; c.f. Beaty and Kerber, 1993). Grain size distributions were measured in a Malvern Mastersizer 2000 sedigraph (Malvern Instruments, 2005).

\section{Statistical analyses}

Each of the radionuclide concentrations was examined for the presence of significant correlation with sampling depth, ages, sample water content and other radionuclide activity concentrations, using the entire available sample collection (100 samples). Using smaller subsamples of 35 samples (25 for the grain size data), which contained the necessary data, various geochemical data (organic carbon content, soil $\mathrm{pH}$ and extractable iron and aluminium concentrations based on dithionite and oxalate extraction agents) and grain size data were examined for correlation with the radionuclide activity concentrations. Lilliefors corrected Kolmogorov-Smirnoff and ShapiroWilk tests of fit between each data set and a normal distribution of data showed that a majority of data sets did not belong to a normal distribution $(\mathrm{p}<0.05)$. In order to calculate the correlation coefficients and their associated probabilities, the Kendall's Tau-b method was employed. SPSS 14.0 software was used for all statistical calculations.

\section{RESULTS AND DISCUSSION}

\section{Characteristics of sample materials}

Physically, the parent materials from the four sampling localities appear very similar; all are well sorted (average $D_{90} / D_{10}: 0.45 \pm 0.02$ ) fine to medium sized sand. Some regional variation in grain size distributions would be expected (c.f. Saye and Pye, 2006), but the differences appear to stem from variation in deposition mechanisms. The predominantly aeolian sands at Jerup and Stensbæk have an average $D_{50}$ of less than $\sim 300 \mu \mathrm{m}$ (Table 1) with $1-2 \%$ fines, while the coarser, predominantly coastal marine deposits at Læsø have an average $D_{50}$ of $357 \pm 9 \mu \mathrm{m}$ and had less than $1 \%$ fines. Based on weight loss during HF digestion, the quartz concentration in the samples is $\sim 90 \%$ by weight. The average dry dose rate for each area is also shown in Table 1. The regional dry dose rate averages illustrate that the source material is not completely homogeneous; values range from $1.06 \pm 0.05 \mathrm{~Gy} / \mathrm{ka}$ (Frøslev) to $1.94 \pm 0.02 \mathrm{~Gy} / \mathrm{ka}$ (Læsø). This variation is mostly due to variations in ${ }^{40} \mathrm{~K}$ activity (Table 2), presumably arising mainly from variations in K-feldspar concentration (Sparks, 1987). The majority of samples are from the Jerup region, with an average dry dose rate close to the mean dose rate for all four regions $(1.43 \pm 0.19 \mathrm{~Gy} / \mathrm{ka})$. All four sampling areas show relatively little scatter in the dose rates ( 1 relative standard deviation from $2 \%$ to $16 \%$ ). As is expected for such well sorted sandy material, these average dose rates are rela- 
Table 1. Average dry dose rates, median grain sizes and percentage of fines for the four major sampling areas in this study with associated standard error margins. The row set in bold at the bottom is the geographical mean. SE is the standard error of the mean. The $n^{*}$ and $n^{* *}$ are referring to the number of samples with available dose rate and grain size data, respectively. The parent material sources are also listed.

\begin{tabular}{lccccccccc}
\hline Area & $\begin{array}{c}\text { Avr. dry } \\
\text { dose rate } \\
(\text { Gy/ka) }\end{array}$ & SE & $\boldsymbol{n}^{*}$ & $\begin{array}{c}\text { Avr. median } \\
\text { grain size }(\mu \mathrm{m})\end{array}$ & SE & $\begin{array}{c}\text { Avr. \% fines } \\
(<100 \mu \mathrm{m})\end{array}$ & SE & $\boldsymbol{n}^{* *}$ & Parent material \\
\hline Jerup & 1.48 & 0.03 & 89 & 239 & 3 & 1.72 & 0.54 & 39 & Aeolian / marine \\
Frøslev & 1.06 & 0.05 & 5 & - & - & - & - & 0 & Aeolian \\
Læsø & 1.94 & 0.02 & 4 & 357 & 9 & 0.89 & 0.35 & 17 & Marine \\
Stensbæk & 1.24 & 0.08 & 2 & 304 & 3 & 1.65 & 0.32 & 2 & Aeolian \\
Mean & $\mathbf{1 . 4 3}$ & $\mathbf{0 . 1 9}$ & $\mathbf{1 0 0}$ & $\mathbf{3 0 0}$ & $\mathbf{3 4}$ & $\mathbf{1 . 4 2}$ & $\mathbf{0 . 2 7}$ & $\mathbf{5 8}$ & \\
\hline
\end{tabular}

Table 2. Estimation of dose rate sources (Gy/ka) and their relative contribution to the local dose rates (\%). The sources are based on average ${ }^{238} \mathrm{U}$, ${ }^{232} \mathrm{Th}$ and ${ }^{40} \mathrm{~K}$ activities measured by gamma spectrometry. Each contribution from the various sources is presented as percentages of the average dry dose rate for that area. The lower row (in bold) presents the geographical mean values.

\begin{tabular}{|c|c|c|c|c|c|c|c|c|c|c|}
\hline \multirow{2}{*}{ Area } & \multicolumn{2}{|c|}{$238 \mathrm{U}$ decay series } & \multicolumn{2}{|c|}{ 232Th decay series } & \multicolumn{2}{|c|}{${ }^{40} \mathrm{~K}$ decay } & \multicolumn{2}{|c|}{ Internal activity } & \multicolumn{2}{|c|}{ Cosmic rays } \\
\hline & Gy/ka & $\%$ & Gy/ka & $\%$ & Gy/ka & $\%$ & Gy/ka & $\%$ & Gy/ka & $\%$ \\
\hline $\begin{array}{l}\text { Jerup, } n=89 \\
\text { (SE) }\end{array}$ & $\begin{array}{c}0.08 \\
(0.07)\end{array}$ & $\begin{array}{l}4.8 \\
(4.5)\end{array}$ & $\begin{array}{l}0.08 \\
(0.01)\end{array}$ & $\begin{array}{l}4.7 \\
(0.4)\end{array}$ & $\begin{array}{l}1.09 \\
(0.03)\end{array}$ & $\begin{array}{l}67.2 \\
(1.6)\end{array}$ & $\begin{array}{l}0.06 \\
(0.03)\end{array}$ & $\begin{array}{l}3.7 \\
(1.8)\end{array}$ & $\begin{array}{c}0.21 \\
(0.01)\end{array}$ & $\begin{array}{l}12.9 \\
(0.2)\end{array}$ \\
\hline $\begin{array}{l}\text { Frøslev, } n=5 \\
\text { (SE) }\end{array}$ & $\begin{array}{l}0.08 \\
(0.07)\end{array}$ & $\begin{array}{l}6.8 \\
(5.9) \\
\end{array}$ & $\begin{array}{l}0.07 \\
(0.01)\end{array}$ & $\begin{array}{l}6.6 \\
(0.5) \\
\end{array}$ & $\begin{array}{l}0.68 \\
(0.02) \\
\end{array}$ & $\begin{array}{l}60.5 \\
(0.5) \\
\end{array}$ & $\begin{array}{l}0.06 \\
(0.03)\end{array}$ & $\begin{array}{c}5.4 \\
(2.7) \\
\end{array}$ & $\begin{array}{l}0.19 \\
(0.01) \\
\end{array}$ & $\begin{array}{l}12.4 \\
(0.3) \\
\end{array}$ \\
\hline $\begin{array}{l}\text { LæS } \emptyset, n=4 \\
(S E)\end{array}$ & $\begin{array}{l}0.19 \\
(0.05)\end{array}$ & $\begin{array}{l}8.7 \\
(2.3)\end{array}$ & $\begin{array}{l}0.12 \\
(0.01)\end{array}$ & $\begin{array}{l}5.8 \\
(0.2)\end{array}$ & $\begin{array}{l}1.42 \\
(0.02)\end{array}$ & $\begin{array}{l}66.2 \\
(0.9)\end{array}$ & $\begin{array}{l}0.06 \\
(0.03)\end{array}$ & $\begin{array}{l}2.8 \\
(1.4)\end{array}$ & $\begin{array}{c}0.21 \\
(0.01)\end{array}$ & $\begin{array}{l}13.0 \\
(0.2)\end{array}$ \\
\hline $\begin{array}{l}\text { Stensbæk, } n=2 \\
(S E)\end{array}$ & $\begin{array}{l}0.09 \\
(0.04) \\
\end{array}$ & $\begin{array}{l}7.0 \\
(2.9)\end{array}$ & $\begin{array}{l}0.09 \\
(0.01)\end{array}$ & $\begin{array}{c}7.1 \\
(0.3) \\
\end{array}$ & $\begin{array}{l}0.80 \\
(0.01) \\
\end{array}$ & $\begin{array}{l}62.1 \\
(1.1) \\
\end{array}$ & $\begin{array}{l}0.06 \\
(0.03)\end{array}$ & $\begin{array}{c}4.6 \\
(2.3) \\
\end{array}$ & $\begin{array}{l}0.23 \\
(0.01) \\
\end{array}$ & $\begin{array}{l}14.6 \\
(0.3) \\
\end{array}$ \\
\hline $\begin{array}{l}\text { Geographical mean } \\
\text { (SE) }\end{array}$ & $\begin{array}{l}0.11 \\
(0.03) \\
\end{array}$ & $\begin{array}{c}6.8 \\
(0.8) \\
\end{array}$ & $\begin{array}{l}0.09 \\
(0.01) \\
\end{array}$ & $\begin{array}{l}6.0 \\
(0.5) \\
\end{array}$ & $\begin{array}{l}1.00 \\
(0.17) \\
\end{array}$ & $\begin{array}{l}64.0 \\
(1.6) \\
\end{array}$ & $\begin{array}{l}0.06 \\
(0)\end{array}$ & $\begin{array}{c}4.1 \\
(0.6) \\
\end{array}$ & $\begin{array}{l}0.21 \\
(0.01) \\
\end{array}$ & $\begin{array}{l}13.2 \\
(0.5) \\
\end{array}$ \\
\hline
\end{tabular}

tively low; for comparison, Olley et al. (1996) examine a "typical" sand/silt sediment mixture with a dose rate of $2.95 \mathrm{~Gy} / \mathrm{ka}$, excluding contributions from cosmic rays and internal activity.

The relative contributions of the three main radioactive decay series, as well as an estimated contribution from internal quartz grain radioactivity and extraterrestrial cosmic gamma rays, are summarised in Table 2. The dry dose rate contributions assume secular equilibrium, even though perfect secular equilibrium is almost never achieved (Krbetschek et al., 1994). A natural ${ }^{238} \mathrm{U} /{ }^{235} \mathrm{U}$ isotopic ratio has also been assumed, but no contribution from ${ }^{87} \mathrm{Rb}$ has been included.

In study that examined gamma spectrometry results from more than 3700 samples, Ankjærgaard and Murray (2007) found that in $95 \%$ of the samples, ${ }^{40} \mathrm{~K}$ contributed $40-92 \%$ of total beta dose rate and $16-76 \%$ of the total gamma dose rate, with the latter dose rate being about one third of the sum of beta and gamma dose rates. A similar distribution is found in this study; $61-67 \%$ of the total dry dose rate originates with ${ }^{40} \mathrm{~K}$, while the ${ }^{238} \mathrm{U}$ and ${ }^{232}$ Th decay series contribute only around $5-9 \%$ each. The cosmic ray dose rate contributes $13-15 \%$ of the total. Finally a small fraction of the total dry dose rate stems from internal alpha radiation, which contributes $3-5 \%$ of the dose rate. This domination of total dose rates by ${ }^{40} \mathrm{~K}$ can be attributed to the relatively low activity concentrations of the ${ }^{238} \mathrm{U}$ and ${ }^{232} \mathrm{Th}$ series. The ${ }^{40} \mathrm{~K}$ activity concentration found here is $\sim 80 \%$ of the ${ }^{40} \mathrm{~K}$ activity found by Olley et al. (1996), i.e. at a comparable level, whereas the ${ }^{238} \mathrm{U}$ and ${ }^{232} \mathrm{Th}$ decay series activities from this study are only $\sim 10 \%$ of the corresponding activities from Olley et al. (1996). As a result, the average dry dose rate from this study is much lower, and the relative contributions from cosmic rays and internal activity much more significant. However, Ankjærgaard and Murray (2007) calculated the modal and median activity concentrations of 3758 samples. Based on these values, the modal dose rate of the 3758 samples was $1.43 \mathrm{~Gy} / \mathrm{ka}$ and the median dose rate was $1.79 \mathrm{~Gy} / \mathrm{ka}$, both well within the range of dose rates found in this study.

\section{Interrelations of the radionuclide activities}

While a plot of one radionuclide activity concentration against another (or a calculation of a correlation coefficient) can be used to deduce some conclusions about the coexistence of the radionuclides, these correlations should not be mistaken for actual chemical interactions among the radionuclides. Chemically, ${ }^{226} \mathrm{Ra},{ }^{232} \mathrm{Th}$ and ${ }^{40} \mathrm{~K}$ behave very differently (Hansen and Huntington, 1969; Sadusky et al., 1987). However, any correlations between radionuclide concentrations allow some conclusions about the likely location of the radionuclides to be drawn, in particular whether the radionuclides are internally bound within silicate minerals, or associated with surface coatings. In the present data set, the ${ }^{226} \mathrm{Ra}$ and ${ }^{232} \mathrm{Th}$ activity concentrations clearly correlate (Kendall's Tau-b coefficients: $0.625 ; \mathrm{p}<0.001 ;$ Table 3 and Fig. 2A). While ${ }^{40} \mathrm{~K}$ and ${ }^{226} \mathrm{Ra}$ or ${ }^{232} \mathrm{Th}$ also correlate significantly (Kendall's Tau-b coefficients: 0.257-0.284; p $<0.001$; Table 3), Fig. 2B and Fig. 3 reveal that these correlations are less straightforward than the ${ }^{226} \mathrm{Ra}$ and ${ }^{232} \mathrm{Th}$ correlation, with a clear intercept on the ${ }^{40} \mathrm{~K}$ axis. Given that the most common minerals in such sandy sediments are quartz and feldspars, and disregarding the 
possibility of surface bound radionuclides (discussed below), we conclude that both the uranium and thorium series nuclides must be bound within feldspar grains (because the internal radioactivity of quartz grains is negligible). Thus the range of uranium, thorium and potassium activity concentrations is likely to arise, at least in part, from variations in the feldspar/quartz ratio in the parent material, because feldspars (and to a lesser degree accessory minerals) must be the primary source of these radionuclides. Changing the quartz concentration would then affect the activity concentrations of ${ }^{226} \mathrm{Ra}$ and ${ }^{232} \mathrm{Th}$ inversely. The very different correlation with potassium

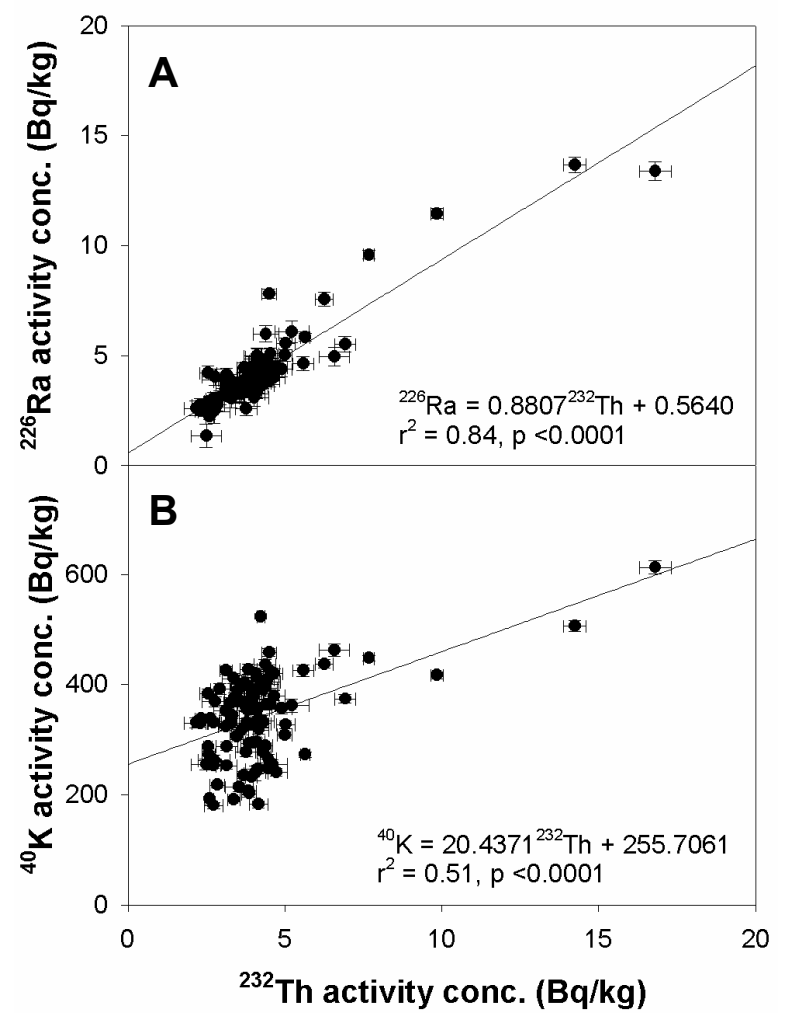

Fig. 2. Plots of ${ }^{232} \mathrm{Th}$ vs. ${ }^{226} \mathrm{Ra}$ (graph A) and ${ }^{232} \mathrm{Th}$ vs. ${ }^{40} \mathrm{~K}$ (graph B) activity concentrations. $A$ linear regression based on all data points has been added to both graphs.

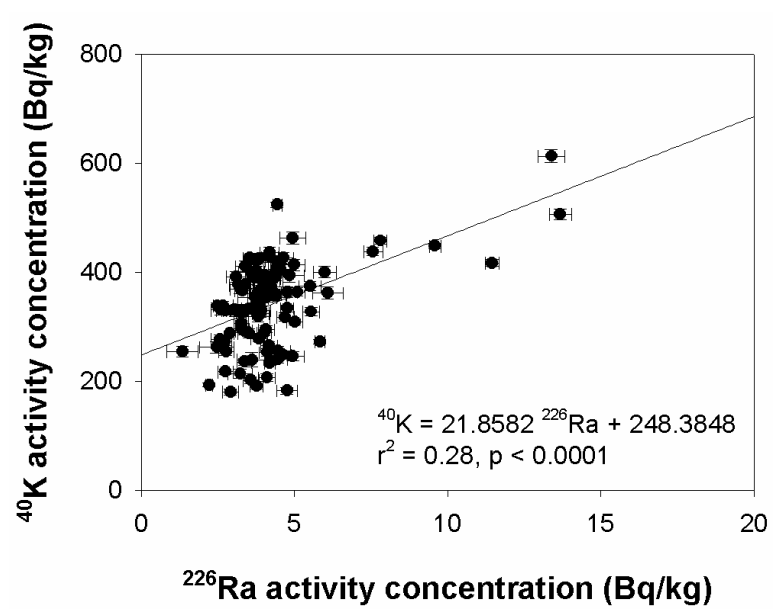

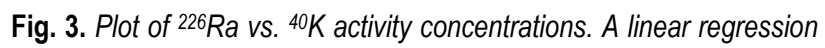
based on all data points has been added. can be partly explained by ${ }^{40} \mathrm{~K}$ originating exclusively with K-feldspars, while ${ }^{226} \mathrm{Ra}$ and ${ }^{232} \mathrm{Th}$ are presumably associated with both $\mathrm{Na}$ - and $\mathrm{K}$-feldspars. If this is true, a plot of ${ }^{226} \mathrm{Ra}$ and ${ }^{232} \mathrm{Th}$ activity concentrations normalized to ${ }^{40} \mathrm{~K}$ should show a reduced scatter compared to the simple ${ }^{226} \mathrm{Ra}$ to ${ }^{232} \mathrm{Th}$ activity concentration plot. Such normalisation (Fig. 4) reduces the standard deviation from $46 \%$ of the mean to $34 \%$, supporting the hypothesis that some of the variability in activity is caused by variations in K-feldspar concentrations. The remaining scatter is presumed to arise from variations in the concentrations of Na-feldspars and accessory minerals.

\section{Radionuclide relations with physical parameters}

While sampling depth in itself should not affect the radionuclide distribution, depth may indicate correlation of the radionuclide concentrations with other depthdependent parameters. ${ }^{226} \mathrm{Ra}$ does not correlate with depth, ${ }^{232} \mathrm{Th}$ has a significant, positive correlation with depth and ${ }^{40} \mathrm{~K}$ correlates inversely with depth (Table 3 ). In principle, higher ${ }^{40} \mathrm{~K}$ concentrations in the topsoil could be a product of potassium fertilizer applied to nearby fields, leading to aerial deposition of $\mathrm{K}$ (and ${ }^{40} \mathrm{~K}$ ) at the soil surface, although mass balance arguments make this very unlikely. These relations might also stem from deposition of ${ }^{232} \mathrm{Th}$ at greater depths, perhaps in association with colloids in groundwater.

Apparent age also seems to affect the radionuclide concentrations, which have inverse correlations with age, indicating that parent materials change and that the new materials are more radioactive. Another observation is that water contents appear to have no effect on radionuclide concentrations, as none of the radionuclides has significant correlations with modern water contents.

Grain size was expected to affect the radionuclide concentrations to some extent, as fine-grained sediment should contain more radionuclide-containing secondary minerals and surface-bound activity, and less nonradioactive quartz. Nevertheless, grain size distributions and their derivatives generally seem to show little correlation with the radionuclide activity concentrations, although the ${ }^{232} \mathrm{Th}$ activity concentration has a significant

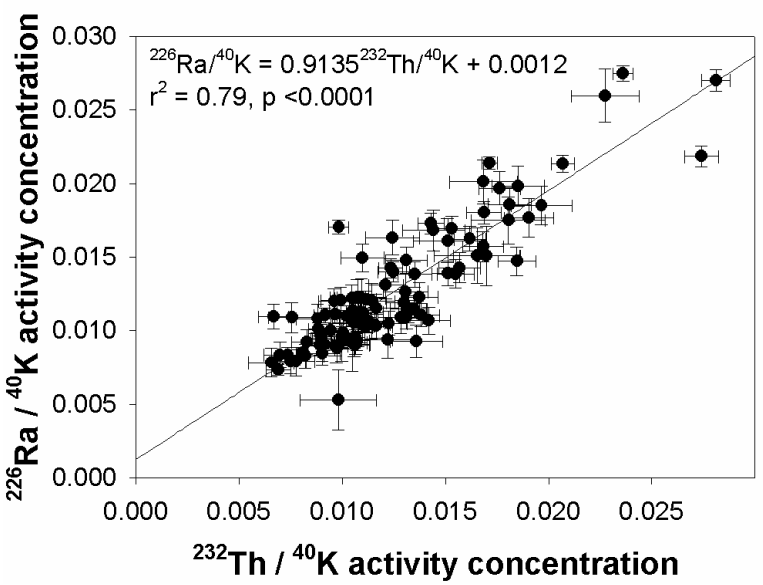

Fig. 4. ${ }^{226} \mathrm{Ra}$ vs. ${ }^{232} \mathrm{Th}$ activity concentration plot, normalised by ${ }^{40 \mathrm{~K}}$ activity concentrations. A linear regression based on all data points has been added. 
Table 3. Two-tailed Kendall's Tau-b correlation coefficients with associated probabilities for the three main radionuclide activity concentrations vs. each other, selected physical and geochemical parameters, respectively. Significant $(p<0.05)$ coefficients are set in bold text. Water content refers to the modern water content of the samples. Fe, $A l_{o}, F e_{d}$ and $A l_{d}$ refer to extractable iron and aluminium by oxalate (o) and dithionite $(d)$. $D_{50}$ is the median grain size. $D_{90} / D_{10}$ is the 90 th grain size distribution percentile divided by the 10th percentile.

\begin{tabular}{|c|c|c|c|}
\hline & ${ }^{226} \mathrm{Ra}$ & 232Th & ${ }^{40} \mathrm{~K}$ \\
\hline \multicolumn{4}{|l|}{$n=100$} \\
\hline${ }^{232} \mathrm{Th}$ & $\begin{array}{c}0.625 \\
p<0.001\end{array}$ & - & - \\
\hline${ }^{40} \mathrm{~K}$ & $\begin{array}{c}0.284 \\
p<0.001\end{array}$ & $\begin{array}{c}0.257 \\
p<0.001\end{array}$ & - \\
\hline Sampling depth & $\begin{array}{c}0.116 \\
p=0.094\end{array}$ & $\begin{array}{c}0.199 \\
p=0.004\end{array}$ & $\begin{array}{c}-0.135 \\
p=0.050\end{array}$ \\
\hline OSL age & $\begin{array}{c}=0.207 \\
p=0.002\end{array}$ & $\begin{array}{c}-0.130 \\
p=0.056\end{array}$ & $\begin{array}{c}-0.304 \\
p<0.001\end{array}$ \\
\hline Water content & $\begin{array}{c}0.118 \\
p=0.081\end{array}$ & $\begin{array}{c}0.071 \\
p=0.299\end{array}$ & $\begin{array}{c}0.041 \\
p=0.549\end{array}$ \\
\hline \multicolumn{4}{|l|}{$n=35$} \\
\hline Org. C & $\begin{array}{c}-0.227 \\
p=0.057\end{array}$ & $\begin{array}{c}-0.390 \\
p=0.001\end{array}$ & $\begin{array}{c}-0.064 \\
p=0.589\end{array}$ \\
\hline $\mathrm{pH}$ & $\begin{array}{c}0.166 \\
p=0.164\end{array}$ & $\begin{array}{c}0.227 \\
p=0.057\end{array}$ & $\begin{array}{c}0.186 \\
p=0.118\end{array}$ \\
\hline $\mathrm{Fe}_{\circ}$ & $\begin{array}{c}0.039 \\
p=0.744\end{array}$ & $\begin{array}{c}0.053 \\
p=0.659\end{array}$ & $\begin{array}{c}0.093 \\
p=0.434\end{array}$ \\
\hline $\mathrm{Al}_{\circ}$ & $\begin{array}{c}-0.190 \\
p=0.111\end{array}$ & $\begin{array}{c}-0.149 \\
p=0.211\end{array}$ & $\begin{array}{c}-0.285 \\
p=0.017\end{array}$ \\
\hline $\mathrm{Fe}_{\mathrm{d}}$ & $\begin{array}{c}0.098 \\
p=0.416\end{array}$ & $\begin{array}{c}0.119 \\
p=0.325\end{array}$ & $\begin{array}{c}0.095 \\
p=0.432\end{array}$ \\
\hline $\mathrm{Al}_{d}$ & $\begin{array}{c}-0.247 \\
p=0.040\end{array}$ & $\begin{array}{c}-0.130 \\
p=0.279\end{array}$ & $\begin{array}{c}-0.326 \\
p=0.007\end{array}$ \\
\hline \multicolumn{4}{|l|}{$n=25$} \\
\hline$D_{50}$ & $\begin{array}{c}0.200 \\
p=0.161\end{array}$ & $\begin{array}{c}0.300 \\
p=0.036\end{array}$ & $\begin{array}{c}0.013 \\
p=0.926\end{array}$ \\
\hline Fines $(<100 \mu \mathrm{m})$ & $\begin{array}{c}-0.272 \\
p=0.068\end{array}$ & $\begin{array}{c}-0.301 \\
p=0.044\end{array}$ & $\begin{array}{c}0.007 \\
p=0.962\end{array}$ \\
\hline $\mathrm{D}_{90} / \mathrm{D}_{10}$ & $\begin{array}{c}-0.040 \\
p=0.779\end{array}$ & $\begin{array}{c}-0.087 \\
p=0.544\end{array}$ & $\begin{array}{c}0.280 \\
p=0.050\end{array}$ \\
\hline
\end{tabular}

correlation with $\mathrm{D}_{50}$ (Kendall's Tau-b coefficient: 0.300; $\mathrm{p}=0.036$; Table 3) and a significant, inverse correlation with the percentage of fines $(<100 \mu \mathrm{m}$; Kendall's Tau-b coefficient: $-0.301 ; p=0.044)$. This suggests that the ${ }^{232} \mathrm{Th}$ activity concentrations increase as the sediment becomes coarser. Similarly, ${ }^{40} \mathrm{~K}$ activity concentrations correlate significantly with $\mathrm{D}_{90} / \mathrm{D}_{10}$ relations (Kendall's Tau-b coefficient: $0.280 ; \mathrm{p}=0.050$ ), indicating that ${ }^{40} \mathrm{~K}$ activity concentrations increase as the sediment becomes less well sorted. However, the radionuclide activity concentrations are also higher in the younger sediments, and as the coarsest samples in this study are relatively young, the grain size-radionuclide concentration correlation could be a product of the chronological distribution of coarse-grained source material. As some of the coarse (younger) samples are marine sands (rather than aeolian), a shift in parent material could explain the correlations between radionuclide activity concentrations and sediment coarseness.

\section{Radionuclide relations with organic $\mathrm{C}$ and $\mathbf{p H}$}

The second set of correlations, based on 35 samples, correlates the three radionuclide activity concentrations with various geochemical data (Table 3). As stated previously, radionuclides can be associated with organic matter, and so one might expect a positive correlation between organic $\mathrm{C}$ concentration correlations and radionuclide activity concentrations. However, ${ }^{226} \mathrm{Ra}$ and ${ }^{40} \mathrm{~K}$ activity concentrations are not significantly correlated with organic $\mathrm{C}$ (Kendall's Tau-b coefficient: -0.227 and $-0.064 ; p=0.057$ and $p=0.589$, respectively); the sole exception to this is the organic $\mathrm{C} /{ }^{232} \mathrm{Th}$ concentration correlation, which shows a highly significant inverse correlation. Such a correlation can be explained by the strong tendency of organic $\mathrm{C}$ concentrations to be inversely correlated with depth (Kendall's Tau-b coefficient: $-0.496 ; \mathrm{p}<0.001)$, while ${ }^{232}$ Th concentrations correlate positively with depth. These correlations with depth can lead to the inverse correlation between organic $\mathrm{C}$ and ${ }^{232}$ Th concentrations. Another explanation might be simple dilution, if the organic matter does not contain significant radionuclide concentrations by itself. In that case, high concentrations of organic matter (as in the topsoil) will result in lower concentrations of the mineral-bound radionuclides. However, if the radionuclides activities are multiplied by the mineral fraction of each sample (assuming that all radionuclides stem from minerals; i.e. that organic material is merely diluting activity concentrations), the correlations with organic $\mathrm{C}$ contents are still insignificant, except for the ${ }^{232} \mathrm{Th} /$ organic $\mathrm{C}$ correlation. The lack of a positive correlation between organic carbon and radionuclide activity concentrations is in agreement with the findings of Morton et al. (2002); they were unable to find any correlations between organic carbon and uranium/thorium contents in their study of podzolised soils in New Hampshire. Furthermore, Yeager and Santschi (2003) did not find any correlation between four out of five different radionuclides and organic carbon content in a study of the soils in the Loco Bayou watershed in eastern Texas. In the latter study, ${ }^{210} \mathrm{~Pb}$ did correlate with organic carbon, but this was attributed to ${ }^{210} \mathrm{~Pb}$ atmospheric deposition on the organic carbon-rich topsoil; Yeager and Santschi, 2003).

While varying $\mathrm{pH}$ levels in a soil column could lead to preferential mobilisation and deposition of radionuclides, the absence of correlations in this study suggests that at these sites $\mathrm{pH}$ has had little effect on the radionuclide distribution. Morton et al. (2002) were also unable to find any significant relation between soil $\mathrm{pH}$ and uranium/thorium contents.

\section{Radionuclide relations with secondary iron and alu- minium minerals}

The most obvious product of soil development, the formation of secondary mineral surface coatings on the primary mineral grains (leading to the colouration of the soil), is potentially important in the redistribution of radionuclides in soils. It is well known (e.g. Hansen and Huntington, 1969; Hansen and Stout, 1968) that coprecipitation of secondary minerals and radionuclides (in the subsoil) does occur, although is it not necessarily 
significant compared to the resistate concentrations. At our sites, extractable iron does not correlate with any of the three radionuclide concentrations (Table 3; Fig. 5). In this type of parent material, extractable iron is most likely to originate with secondary mineral surface coatings on the primary mineral grains. An increase in extractable iron would imply an increased degree of weathering and so soil development. By plotting CBD-extractable iron (which includes all non-silicic iron fractions) against the activity concentrations of ${ }^{226} \mathrm{Ra},{ }^{232} \mathrm{Th}$ and ${ }^{40} \mathrm{~K}$, it is possible to check whether any of these radionuclides is primarily surface bound - such association would lead to a clear correlation. The absence of correlation must indicate that the radionuclides are not associated with surfaces, and thus must be mainly internally bound in the silicate minerals. These findings are consistent with those of Yeager and Santschi (2003) who also found that the subsoil accumulation of secondary iron and aluminium minerals appeared to have little or no effect on the distribution of radionuclides from the ${ }^{238} \mathrm{U}$ and ${ }^{232}$ Th series in the soil.

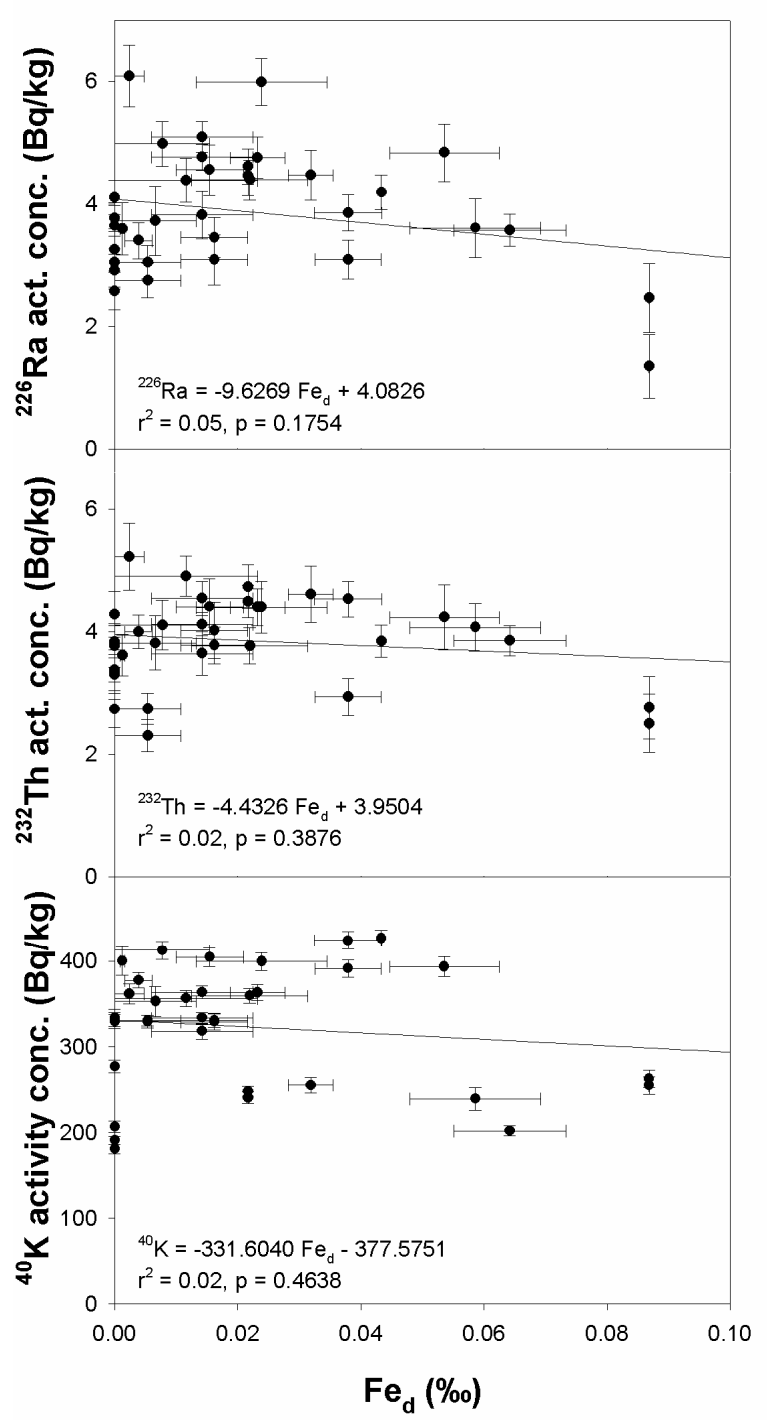

Fig. 5. ${ }^{226} \mathrm{Ra},{ }^{232} \mathrm{Th}$ and ${ }^{40} \mathrm{~K}$ activity concentrations plotted against $\mathrm{CBD}$-extracted iron $\left(\mathrm{Fe}_{d}\right)$ concentrations. A linear regression based on all data points has been added.
Extractable aluminium concentrations indicate some inverse correlations with ${ }^{40} \mathrm{~K}$ activity concentrations (oxalate - Kendall's Tau-b coefficient: $-0.285, \mathrm{p}=0.017$; CBD - Kendall's Tau-b coefficient: $-0.326, \mathrm{p}=0.007$ ) and ${ }^{226} \mathrm{Ra}$ (CBD only, Kendall's Tau-b coefficient: $-0.247, p=0.040)$. Extractable Al presumably reflects, at least in part, the degree of weathering of feldspar minerals, and it is likely that the more weathered material will tend to be relatively low in feldspar (and thus in primarybound K). Potassium and aluminium would normally coprecipitate to form secondary $\mathrm{K}-\mathrm{Al}$ minerals (Parker et al., 1989), which would lead to a positive correlation of ${ }^{40} \mathrm{~K}$ and extractable aluminium. However, in the acidic conditions of these soils, potassium is presumably readily leached and removed to ground water.

\section{Results from three soil profiles}

As the correlation matrix analysis (Table 3) and the extractable iron/radionuclide concentration plot (Fig. 5) indicated no general correlation of secondary mineral formation and radionuclide distribution, we chose to examine the data from individual soil profiles separately. These profiles include samples from the horizons with pronounced soil development, which might reveal systematic dependencies otherwise masked in larger datasets with many samples from other horizon types. This study includes data from three profiles (Fig. 6). The ${ }^{226} \mathrm{Ra}$ and ${ }^{232} \mathrm{Th}$ concentrations tend to increase with depth in all three profiles. The same trend is demonstrated by the ${ }^{40} \mathrm{~K}$ activity concentration in Profile 3 (Fig. 6C). The ${ }^{226} \mathrm{Ra}$ and ${ }^{232} \mathrm{Th}$ activity concentrations follow each other closely in the range $2-7 \mathrm{~Bq} / \mathrm{kg} .{ }^{40} \mathrm{~K}$ activity concentrations are at a much higher level around $300 \mathrm{~Bq} / \mathrm{kg}$, but generally mimic the other two radionuclide activity concentrations.

The radionuclide activity concentrations in the eluvial and illuvial soil horizons formed by podzolisation appear unaffected by soil development. In profiles 2 and 3, no deviations from the general trend are seen, while Profile 1 has a slight increase in the ${ }^{226} \mathrm{Ra}$ activity concentration, corresponding with that in the Bhs horizons. Immediately below, in the Bs horizon, ${ }^{40} \mathrm{~K}$ is somewhat lower than average, but just slightly above the range covered by the scatter in ${ }^{40} \mathrm{~K}$ activity concentrations through the profile. The lack of marked effects on the radionuclide activity concentration is in contrast to the findings of Hansen and Stout (1968), who observed a peak in uranium and especially thorium concentrations in podzolised soils in California. The lowered concentrations of thorium in the $\mathrm{E}$ horizons as observed by Hansen and Huntington (1969) were not found in any of the profiles from this study. Vandenbygaart and Protz (1995) experienced higher activity concentrations of ${ }^{214} \mathrm{Bi},{ }^{208} \mathrm{Tl}\left({ }^{232} \mathrm{Th}\right.$-daughter $)$ and ${ }^{40} \mathrm{~K}$ in three well-developed spodic horizons, and to some extent in two weakly podzolic horizons. The latter observations suggest that radionuclide activity concentrations may be greater in soils with more developed spodic horizons. However, in our study, only one small concentration peak in a spodic horizon was observed in one out of three profiles, even though Profile 1 displayed a moderate degree of podzolisation, just as Profile 2, and Profile 3 contained a strongly developed spodic horizon. 
Age (ka)

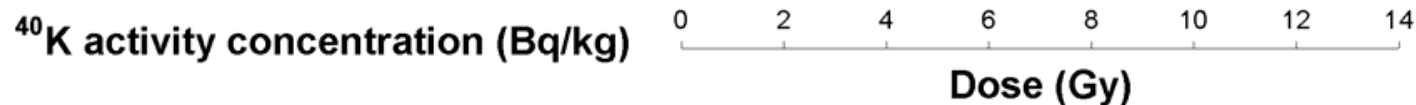

\begin{tabular}{lllllllll}
0 & 100 & 200 & 300 & 0 & 5 & 10 & 15 & 20 \\
\hline & 1 & 1 & 15
\end{tabular}

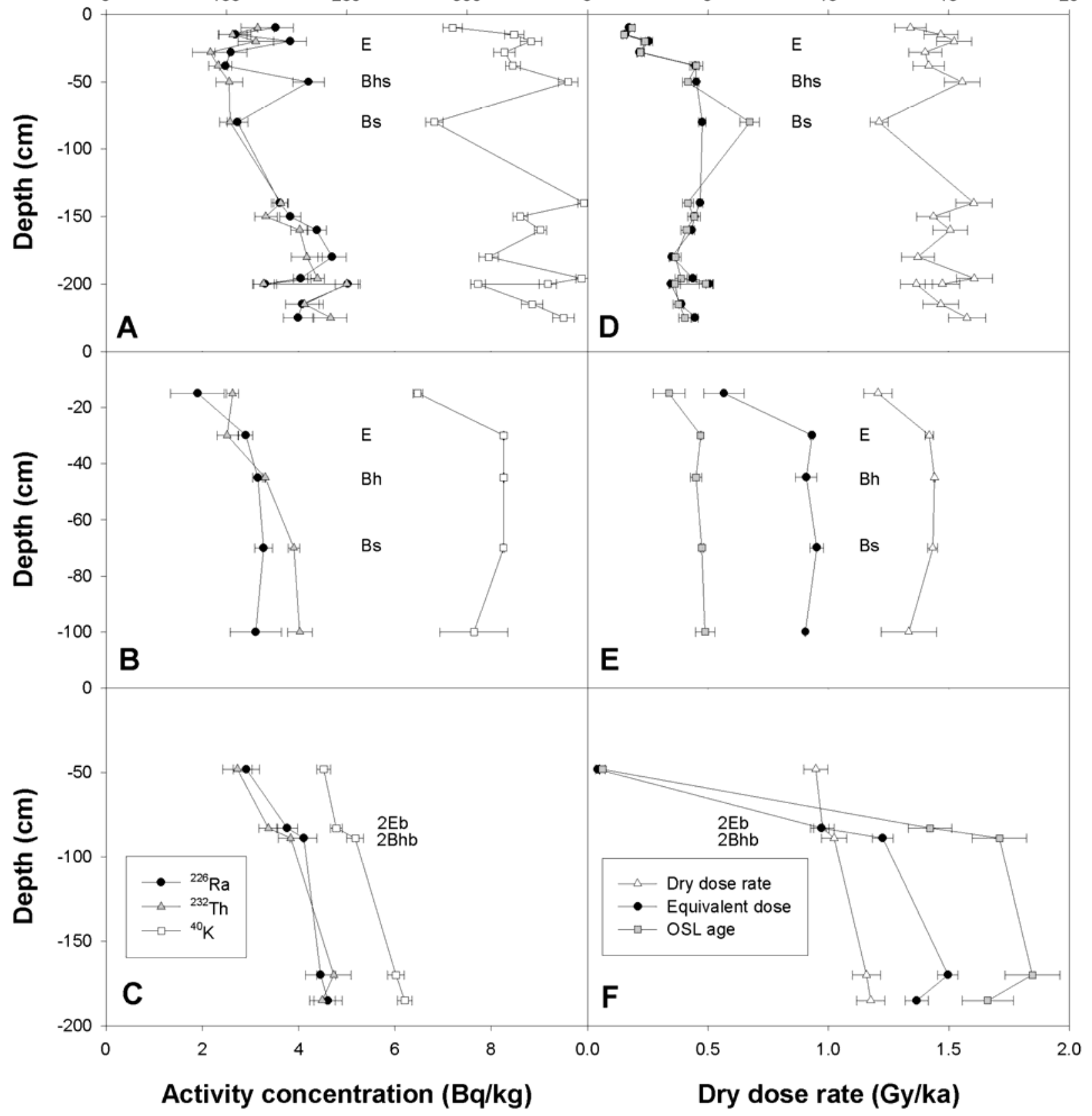

Fig. 6. Profile radionuclide activity concentrations, equivalent doses and dry dose rates. Graphs $A$ and $D$ present data from Profile 1 , graphs $B$ and $E$ contain data from Profile 2 and graphs $C$ and $F$ illustrate data from Profile 3. Graphs A, B and C display activity concentrations of ${ }^{226} R a,{ }^{232} T h$ and ${ }^{40} \mathrm{~K}$, while $D, E$ and $F$ show equivalent doses, dry dose rates and apparent ages. The vertical locations of eluvial and illuvial horizons associated with podzolisation are indicated by horizon letters (e.g. "E").

Because the ${ }^{40} \mathrm{~K}$ contribution dominates the beta and gamma dose rates, the dry dose rate across all three profiles follows the ${ }^{40} \mathrm{~K}$ concentration closely (Fig. 6). Hence, soil formation-related redistributions of ${ }^{40} \mathrm{~K}$ in the soil profiles could have a significant effect on the dose rate, eventually affecting the luminescence age determination. Nevertheless, the ${ }^{40} \mathrm{~K}$ concentration does tend to follow variations in the other radionuclides, with two major exceptions. Firstly, the uppermost parts of Profiles
1 and 2 display lower concentrations of ${ }^{40} \mathrm{~K}$, which could be a result of leaching of K-containing feldspars; topsoils have the highest concentrations of organic acids (lowest $\mathrm{pH}$ values, as seen in Fig. 7) and these can contribute to the weathering of feldspars and other minerals. As previously mentioned, plant uptake of $\mathrm{K}$ (which would highest in the topsoils) is unlikely to affect total ${ }^{40} \mathrm{~K}$ activity concentrations as the amount of $\mathrm{K}$ in plant materials is less than $0.5 \%$ of the total K content in soils. Secondly, the 
${ }^{40} \mathrm{~K}$ concentration in the Bs horizon of Profile 1 is almost $100 \mathrm{~Bq} / \mathrm{kg}$ below the average of the remaining samples in that profile. Kubica et al. (2005) found a similar pattern for ${ }^{40} \mathrm{~K}$ concentrations in podzolised soil profiles in Poland, where the ${ }^{40} \mathrm{~K}$ concentration were lowest in the $\mathrm{Bh}$ and Bs horizons; this was thought to be probably due to the relatively high organic and non-silicate mineral composition of these horizons, diluting the ${ }^{40} \mathrm{~K}$ concentration, which mainly originates from K-containing silicates.

Additional geochemical results are available at Profiles 2 and 3 (Fig. 7). At both profiles, it is evident that translocation of organo-aluminium compounds has taken place, generating a pronounced secondary peak of organic $\mathrm{C}$ and extractable aluminium concentrations in the spodic $\mathrm{Bh}$ horizons and a low in these concentrations in the E horizons. The soil $\mathrm{pH}$ is acidic throughout the profiles, with the topsoils having the lowest $\mathrm{pH}$ values. The extractable iron concentrations are low throughout the profile, and do not peak in the spodic horizons, indicating that the sediment is relatively iron-poor, or that the iron has not yet been freed from non-extractible locations (mainly silicate minerals). Nevertheless, the colouring of the soil indicate that some iron has been translocated, as dark-coloured spodic horizons were encountered at many sampling sites and most soil sections are yellowish brown or reddish brown (i.e. typical colours of iron mineral

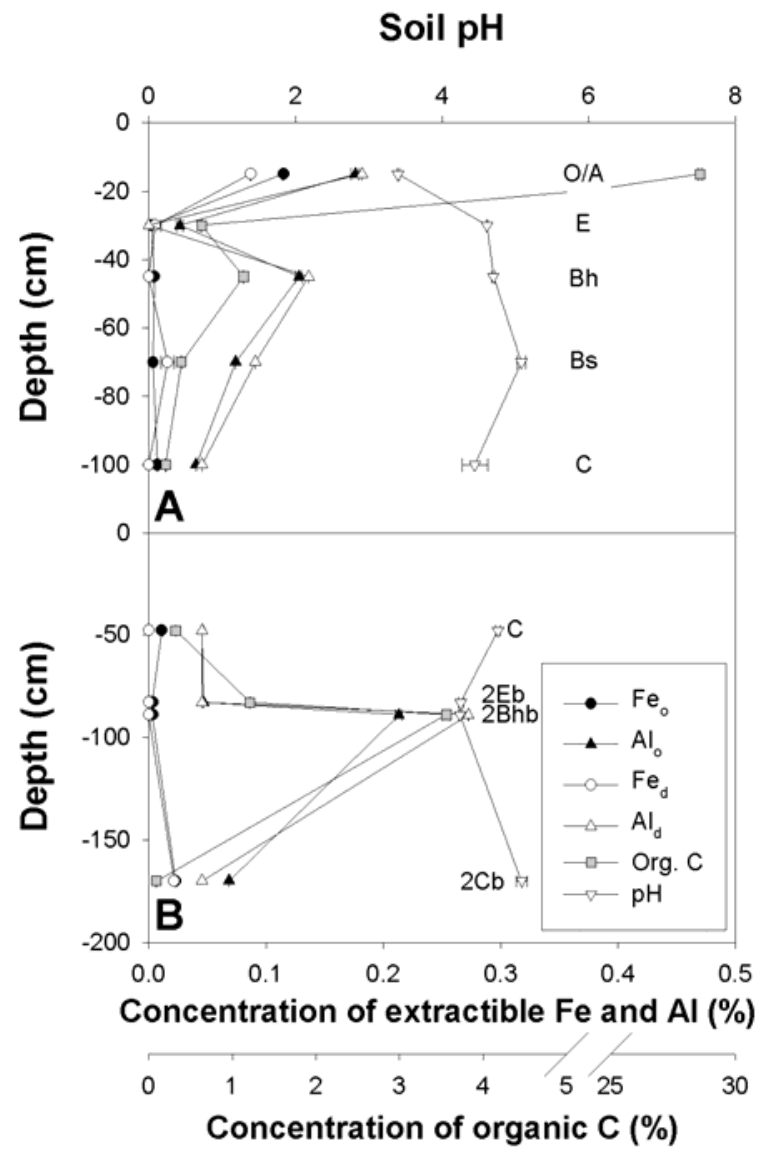

Fig. 7. Additional soil geochemical data for Profile 2 (graph A) and Profile 3 (graph B). Each graph illustrate the soil $\mathrm{pH}$, concentrations of extractible Fe/Al (using two extraction agents, dithionite (CBD) " $d$ " and ammonium oxalate "o") and organic carbon content. coatings), and not the grey-white colour of pure quartz grains. Despite the colouration and ortstein cementation at some sites, the lack of evidence for iron and radionuclide translocation combined with the relatively young soil ages (generally below 4000 years) suggest that the soils in this study are simply not developed enough to see significant weathering of the radionuclide-containing feldspars.

\section{Radionuclide sources in the samples}

If we assume that virtually all potassium in the samples is bound in minerals (c.f. Parker et al., 1989), K will be present in primary mineral K-feldspars and secondary mineral micas (Sparks, 2000). From the grain size data, the sandy samples of this study have very little clay contents (Table 1). In addition, given the long sedimentary history of the samples (multiple deposition and erosion cycles), the samples will be dominated by weatheringresistant minerals such as quartz and K-feldspars, while the softer micas will be broken down into smaller pieces (in these sediments of ultimately marine origin, the fine grains are preferentially washed away in the swash zone by wave action) or disintegrate by chemical weathering. Hence, we now assume that all potassium is bound in $\mathrm{K}$-feldspars only. This assumption implies that the all ${ }^{40} \mathrm{~K}$ activity stems from K-feldspars, which will have an approximate average potassium content by weight of $7 \%$ (average of a minimum content of $0 \%$ and a maximum content in pure microcline and orthoclase of $14.05 \%$ ). Using a conversion factor of $309 \mathrm{~Bq} / \mathrm{kg}$ for $1 \% \mathrm{~K}$, the average ${ }^{40} \mathrm{~K}$ activity concentration in this study $(n=100)$ of $340 \mathrm{~Bq} / \mathrm{kg}$ corresponds to a mean content of $1.1 \% \mathrm{~K}$ in the bulk sample. Following the assumptions above, this concentration corresponds to a mean K-feldspar concentration of $7.7 \%$ in the bulk sample. The quartz concentration measured by etching loss was $\sim 90 \%$, leaving about $10 \%$ to other minerals. The calculated K-feldspar concentration of $7.7 \%$ is well within that range. The remaining $2-3 \%$ of the bulk sample would then be accounted for by Na-feldspars and accessory minerals, as well as simply being errors on our quartz and feldspar content estimates.

Applying similar conversion factors of $12.44 \mathrm{~Bq} / \mathrm{kg}$ and $4.07 \mathrm{~Bq} / \mathrm{kg}$ per ppm of uranium and thorium, respectively, the mean activity concentrations of $4.3 \mathrm{~Bq} / \mathrm{kg}$ for ${ }^{238} \mathrm{U}$ series and $4.1 \mathrm{~Bq} / \mathrm{kg}$ for ${ }^{232} \mathrm{Th}$ series correspond to $\sim 0.3 \mathrm{ppm} \mathrm{U}$ and $\sim 1.0 \mathrm{ppm}$ Th. Both mean concentrations are slightly lower than typical concentrations of $U$ and $T h$ in soils (0.8-4 and 2-16 ppm, respectively; Harmsen and de Haan, 1980; Hansen and Stout, 1968), but still within one order of magnitude of these concentration ranges. We go on to assume that all virtually all uranium and thorium are internally bound in feldspars (they cannot be bound in quartz, and they are not apparently surface bound). These feldspars make up about $7-10 \%$ of the bulk sediment per weight unit (see above), and so the mean $\mathrm{U}$ and Th concentration in the feldspars must be 3-4 and 10-13 ppm, respectively. However, K-feldspars generally have much smaller $\mathrm{U}$ and Th concentrations (3-10\% of the concentrations found here, c.f. Nagpal et al., 1973; Bodet and Schärer, 2001). This discrepancy implies that the uranium and thorium must be associated with other sources than $\mathrm{K}$-feldspars, such as accessory minerals and secondary 
minerals on the surfaces of the primary mineral grains. If the latter exist, they must be very small, and insufficient to affect the extractable iron-radionuclide correlations significantly. This observation supports our general notion that these soils may have seen some redistribution of uranium and thorium together with the soil forming processes, but they are too young to have allowed significant redistribution of these elements.

\section{CONCLUSIONS}

Our results show that the study areas contain homogeneous sandy parent material with relatively low radionuclide activity concentrations (and, in turn, low dose rates) predominantly bound within the grains rather than on grain surfaces. Profile studies did not reveal any systematic correlation between podzolisation-affected soil horizons and radionuclide activity concentrations. These observations were reflected in the absence of significant correlation between radionuclides and organic carbon, soil $\mathrm{pH}$ or extractable iron or (in part) aluminium. Field water content, taken to indicate proximity of groundwater, did not correlate with any of the radionuclide concentrations. Soil development, mainly podzolisation at these locations, should tend to redistribute material associated with secondary minerals or bound on surfaces. This does not appear to be important at these sites, presumably because most radioactivity is still held within primary minerals.

Based on these results, we conclude that in young sandy soils such as these, with low ${ }^{238} \mathrm{U}$ and ${ }^{232}$ Th activity concentrations, and with ${ }^{40} \mathrm{~K}$ dominating the dose rate, time-dependent dose rate variations are unlikely. Collecting OSL samples from such podzolised horizons is unlikely to lead to significant uncertainties in the age arising from post-depositional radionuclide mobilisation.

\section{ACKNOWLEDGEMENTS}

The authors would like to thank the numerous private landowners near Jerup, Kragsskovhede National Prison, the Ammunition Facility in Elling, the Municipality of Frederikshavn and the Danish Forest and Nature Agency (Skov- og Naturstyrelsen) for kindly allowing sample collection from their properties. The technicians at the Department of Geography \& Geology (Copenhagen) and at the Nordic Laboratory for Luminescence Dating (Risø) are also thanked for assisting with laboratory work. We also thank H. Breuning-Madsen, T. Balstrøm, R.S. Dam, B. Elberling, M. Habekost, P. Hauerbach, P.N. Johannesen, M.P. Koue, G. Lyngsie, L.-H. Nielsen, N. NoeNygaard, A. Olesen, M. Pejrup, M.N. Schultz and S. Skibsted for assistance at various field campaigns. The OBS research project (Danish Natural Science Research Council grant no. 272-05-0278 to M. Pejrup, Department of Geography \& Geology, University of Copenhagen) provided funding to this study.

\section{REFERENCES}

Aitken MJ, 1985. Thermoluminescence dating. London, UK, Academic Press: $359 \mathrm{pp}$.
Ankjærgaard C and Murray AS, 2007: Total beta and gamma dose rates in trapped charge dating based on beta counting. Radiation Measurements 42(3): 352-359, DOI 10.1016/j.radmeas.2006.12.007.

Argyilan EP, Forman SL, Johnston JW and Wilcox DA, 2005. Optically stimulated luminescence dating of late Holocene raised strandplain sequences adjacent to Lakes Michigan and Superior, Upper Peninsula, Michigan, USA. Quaternary Research 63(2): 122-135, DOI 10.1016/j.yqres.2004.12.001.

Beaty RD and Kerber JD, 1993. Concepts, instrumentation and techniques in atomic absorption spectrometry. 2. ed. Wellesley, MA, The Perkin-Elmer Corporation. Available at http://las.perkinelmer.com.

Bodet $\mathrm{F}$ and Schärer $\mathrm{U}, 2001$. $\mathrm{Pb}$ isotope systematics and timeintegrated $\mathrm{Th} / \mathrm{U}$ of SE-Asian continental crust recorded by single K-feldspar grains in large rivers. Chemical Geology 177(3-4): 265285, DOI 10.1016/S0009-2541(00)00413-7.

Buurman $\mathrm{P}$ and Jongmans AG, 2005. Podzolisation and soil organic matter dynamics. Geoderma 125(1-2): 71-83, DOI 10.1016/j.geoderma.2004.07.006.

Bøtter-Jensen L, 1997. Luminescence techniques: instrumentation and methods. Radiation Measurements 27(5-6): 749-768, DOI 10.1016/S1350-4487(97)00206-0.

Bøtter-Jensen L, Bulur E, Duller GAT and Murray AS, 2000. Advances in luminescence instrument systems. Radiation Measurements 32(5-6): 523-528, DOI 10.1016/S1350-4487(00)00039-1.

Eltra, 2002. Operation manual CS-500. Neuss, Germany, Eltra GmbH. Available at http://www.eltragmbh.com/manuals.php.

Hansen RO and Huntington GL, 1969: Thorium movements in morainal soils of the High Sierra, California. Soil Science 108: 257-265.

Hansen RO and Stout PR, 1968. Isotopic distributions of uranium and thorium in soils. Soil Science 105: 44-50.

Harmsen K and de Haan FAM, 1980. Occurrence and behaviour of uranium and thorium in soil and water. Netherlands Journal of Agricultural Science 28: 40-62.

Krbetschek MR, Rieser U, Zöller L and Heinicke J, 1994. Radioactive disequilibria in palaeodosimetric dating of sediments. Radiation Measurements 23(2-3): 485-489, DOI 10.1016/13504487(94)90083-3.

Kubica B, Skiba M, Skiba S, Golaś J, Kubica M, Stobiński M and Tuteja-Krysa M, 2005. Dislocation of the ${ }^{137} \mathrm{Cs}$ and ${ }^{40} \mathrm{~K}$ radionuclides in the podzol profiles of the Tatra Mountain soils (South Poland). Journal of Radioanalytical and Nuclear Chemistry 266(1): 3-9, DOI 10.1007/s10967-005-0861-z.

Lundström US, van Breemen N and Bain D, 2000. The podzolization process. A review. Geoderma 94(2-4): 91-107, DOI 10.1016/S0016-7061(99)00036-1.

Malvern Instruments, 2005. Mastersizer 2000. Specification sheet Malvern, UK, Malvern Instruments, Ltd. Available at $\mathrm{http}: / / \mathrm{www} . \mathrm{malvern} . \mathrm{com} / \mathrm{ms} 2000$.

McKeague JA and Day JH, 1966. Dithionite- and oxalate-extractable Fe and $\mathrm{Al}$ as aids in differentiating various classes of soil. Canadian Journal of Soil Science 46: 13-22.

Morton LS, Evans CV and Estes GO, 2002. Natural uranium and thorium distributions in podzolized soils and native blueberry. Journal of Environmental Quality 31: 155-162.

Murray AS and Wintle AG, 2000. Luminescence dating of quartz using an improved single-aliquot regenerative-dose protocol. Radiation Measurements 32(1): 57-73, DOI 10.1016/S1350-4487(99)00253$\mathrm{X}$.

Murray AS and Wintle AG, 2003. The single aliquot regenerative dose protocol: potential for improvements in reliability. Radiation Measurements 37(4-5): 377-381, DOI 10.1016/S13504487(03)00053-2.

Murray AS, Marten R, Johnson A and Martin P, 1987. Analysis for naturally occurring radionuclides at environmental concentrations by gamma spectrometry. Journal of Radioanalytical and Nuclear Chemistry 115(2): 263-288, DOI 10.1007/BF02037443.

Nagpal MK, Nagpaul KK and Mehta PP, 1973. Uranium contents in minerals by fission track method. Pure and Applied Geophysics 102(1): 153-160, DOI 10.1007/BF00876602.

Olley JM, 1994. The use of $238 U$ and 232Th decay series radionuclides in sediment tracing. PhD thesis. Sydney, Australia, University of New South Wales.

Olley JM, Murray AS and Roberts RG, 1996. The effects of disequilibria in the uranium and thorium decay chains on burial dose rates in fluvial sediments. Quaternary Science Reviews 15(7): 751-760, DOI 10.1016/0277-3791(96)00026-1. 
Parker DR, Sparks DL, Hendricks GJ and Sadusky MC, 1989. Potassium in Atlantic coastal plain soils: I. Soil characterization and distribution of potassium. Soil Science Society of America Journal 53: 392-396.

Prescott JR and Hutton JT, 1994: Cosmic ray distributions to dose rates for luminescence and ESR datings: large depths and long-term variations. Radiation Measurements 23(2-3): 497-500, DOI 10.1016/1350-4487(94)90086-8.

Prescott JR and Hutton JT, 1995. Environmental dose rates and radioactive disequilibrium from some Australian luminescence dating sites. Quaternary Science Reviews 14(4): 439-448, DOI 10.1016/0277-3791(95)00037-2.

Sadusky MC, Sparks DL, Noll MR and Hendricks GJ, 1987. Kinetics and mechanisms of potassium release from sandy Middle Atlantic coastal plain soils. Soil Science Society of America Journal 51: 1460-1465.

Saye SE and Pye K, 2006. Variations in chemical composition and particle size of dune sediments along the west coast of Jutland, Denmark. Sedimentary Geology 183(3-4): 217-242, DOI 10.1016/j.sedgeo.2005.09.011.

Scheffer F and Schachtschabel P, 2002. Lehrbuch der Bodenkunde. 15. ed. Heidelberg, Germany, Spektrum Akademischer Verlag: 593pp (in German).

Sparks DL, 1987. Potassium dynamics in soils. In: Stewart B.A., ed., Advances in Soil Science, vol. 6. Springer-Verlag: 1-63.

Sparks DL, 2000. Bioavailability of soil potassium. In: Sumner M.E., ed., Handbook of soil science. Boca Raton, Florida, USA, CRC Press: pp. D38-D53.

Talibudeen O, 1964. Natural radioactivity in soils. Soils and Fertilizers 27: 347-359.

Tan KH, 1996: Soil sampling, preparation and analysis. New York, NY, Marcel Dekker, Inc.

Vandenberghe D, 2004. Investigation of the optically stimulated luminescence dating method for application to young geological sediments. Unpublished $\mathrm{PhD}$ thesis. Ghent, Belgium, Department of Analytical Chemistry, Ghent University.

Vandenbygaart AJ and Protz R, 1995. Gamma radioactivity on a chronosequence, Pinery Provincial Park, Ontario. Canadian Journal of Soil Science 75: 73-84.

Yeager KM and Santschi PH, 2003. Invariance of isotope ratios of lithogenic radionuclides: more evidence for their use as sediment source tracers. Journal of Environmental Radioactivity 69(3): 159176, DOI 10.1016/S0265-931X(03)00068. 